\title{
HOW TO TRAIN SAFE DRIVERS: SETTING UP AND EVALUATING A FATIGUE TRAINING PROGRAM
}

\author{
Giannis Adamos ${ }^{1}$, Eftihia Nathanail ${ }^{2}$ \\ ${ }^{I}$ University of Thessaly, Department of Civil Engineering \\ Pedion Areos, 38334 Volos, Greece \\ Phone: +30 24210 74158.Fax: +302421074131.E-mail: giadamos@civ.uth.gr \\ ${ }^{2}$ University of Thessaly, Department of Civil Engineering \\ Pedion Areos, 38334 Volos, Greece \\ Phone: +30 24210 74164.Fax: +3024210 74131.E-mail: enath@uth.gr
}

\begin{abstract}
Fatigue is considered as a serious risk driving behavior, causing road accidents, which in many cases involve fatalities and severe injuries. According to CARE database statistics, professional drivers are indicated as a high-risk group to be involved in a fatigue-related accident. Acknowledging these statistics, a training program on driving fatigue was organized, aiming at raising awareness of professional drivers of a leading company in building materials, in Greece. Selected experimental methods were used for collecting data before and after the training program, which allowed monitoring and assessing the potential behavioural changes. A questionnaire survey was conducted before the program implementation to 162 drivers of the company, while two months after the program, the same drivers replied to a second questionnaire. Impact assessment of the program relied on statistical analysis of the responses. Results showed the degree of penetration of the training program in the professional drivers' behavior towards safe driving.
\end{abstract}

Keywords: fatigue; program; impact assessment; professional drivers.

\section{Introduction}

Falling asleep at the wheel is one of the leading factors causing road accidents and injuries worldwide. The National Highway Traffic Safety Administration (NHTSA) of the United States of America estimates that there are 56.000 sleep related crashes annually in the USA, resulting in 40.000 injuries and 1.550 fatalities (Royal, 2003). In 2002, in a survey of the same organization, $37 \%$ of drivers reported that they had fallen asleep or nodded off, even for a moment, when driving (NHTSA, 1998). In Australia, VicRoads estimates that $25 \%-35 \%$ of road crashes are sleep related (VicRoads, 2014), while the results of a study by Moller of the University Health Network and the University of Toronto Sleep Research Unit in Canada, showed that driver fatigue is a serious factor hindering road safety, since it causes the death of 400 Canadians every year (Yakabuski, 2014). In China, in 2011, the Traffic Administration Bureau of Chinese Ministry of Public Security reported that 1003 out of 1755 recorded fatigue driving accidents were fatal, meaning that there is almost one death for every two fatigue related accidents (Traffic Administration Bureau of Chinese Public Security Ministry, 2010). At a European level, a study by the Sleep Research Center indicates that driver fatigue causes up to $20 \%$ of accidents on motorways in United Kingdom (Horne \& Reyner, 2000). In Germany, a study of motorway accidents in Bavaria estimated that $35 \%$ of fatal motorway crashes were due to reduced vigilance, i.e. driver inattention and fatigue (Hell et al., 1997). In Finland, the proportion of fatal accidents involving fatigue or falling asleep between 1995 and 1999 was ranging between 16-19\% (ETSC, 2001).

The above statistics validate that driver fatigue is a contributing factor in many accidents, and the gravity of this contribution can be quantified by an average proportion of $20 \%$ of total accidents that are fatigue related (MacLean et al., 2003). Previous studies have also stressed the significant impact of fatigue on driving performance, such as slower reaction times, poor speed control, reduced vigilance, reduced information processing, late corrections to lane positioning, and increased drifting within lane (Otmani et al., 2005).

On the other hand, although drivers do have the ability to recognize when they feel sleepy (Horne $\&$ Baulk, 2004), and they also have extensive knowledge about the factors that cause fatigue while driving, still a significant proportion of them chooses to keep driving. 
Drivers often keep driving while fatigued, adopting several strategies that they may consider as efficient, such as drink a coffee, open the window, listen to music, talk with passengers, stop and rest, however all these strategies are only partially effective in coping with fatigue (Oron-Gilad \& Shinar, 2000). In Royal (2003), it was observed that the most commonly reported coping actions were to pull over and take a nap, open the window and drink a caffeinated drink (Royal, 2003). Mental games or similar actions are also tasks that drivers are engaged in, when they feel fatigued while driving (Maycock, 1997). In the case of professional drivers, a survey conducted by Oron-Gilad and Shinar (2001), showed that over $50 \%$ of the surveyed military truck drivers stated that drinking a coffee or water helps them staying awake, while approximately $40 \%$ of the drivers reported that drinking caffeinated soft drinks and smoking cigarettes work as solutions to encounter fatigue (Oron-Gilad \& Shinar, 2000).

According to literature, specific groups of road users are indicated as of higher risk to be involved in a fatigue-related accident, i.e. young drivers (Horne \& Reyner, 1995), shift workers (Gkrizioti et al., 2010), drivers with sleep disorders (Yee et al., 2002), and professional drivers (McKernon, 2008). Nevertheless, in all types of users, fatigue deteriorates the ability of drivers to control their vehicles, by affecting their attention, reaction and vigilance, increasing in such cases the probability of a road accident occurrence. When drivers choose to drive under fatigue, their behavior is apparently dangerous. Such a dangerous behavior, in the case of professional drivers, could be related to economic rewards (Arnold et al., 1997), but also to other factors that influence their driving performance, including continuous driving time (trip duration), sleep deprivation (bad quality of sleep, lack of sleep, sleep apnoea) and work schedule (night trips, shifts). A number of studies have indicated that driving performance is negatively affected by driving time, which stands as the main factor influencing drivers' abilities (Otmani et al., 2005), along with driving in a monotonous environment and circadian effects (Rossi et al., 2011). In the study of Zhang et al. (2014), the effects of circadian rhythms on driving performance were investigated in an on-road experiment, and results showed that a driver was most likely to feel tired between 14:00-16:00 and 02:00-04:00, time periods during which drivers' ability to stay within designated lane lines was significantly reduced (Zhang et al., 2014). The peak period for driver fatigue between midnight and 06:00 was also indicated in an American study (Blower et al., 1993), which revealed that approximately $20 \%$ of all fatal crashes and fatalities and $10 \%$ of all injuries involving a long-haul truck occurred in this time period.

There is evidence in statistics which shows that professional drivers are at a high risk of road accidents worldwide, i.e. in USA, approximately $25 \%$ of fatal work-related accidents are road traffic incidents (Toscano \& Windau, 1994), while in European countries i.e. Denmark, Finland and Sweden the relevant proportion reaches $20 \%$ (Charbotel et al., 2001). According to CARE database, tiredness is the main factor for $20 \%$ of crashes involving commercial vehicles, one fourteenth of fatalities involving heavy goods vehicles, and more than $10 \%$ of total fatalities involving professional vehicles (CARE, 2014). Similar findings are revealed from self-reported surveys, i.e. in Norway, $10 \%$ of male drivers and $4 \%$ of females stated that they had fallen asleep while driving during the last year (Sagberg, 1999), while the $29 \%$ of respondents in a study in Great Britain, stated that they had felt close to falling asleep while driving in the past year (Maycock, 1997).

Three main categories of driving fatigue countermeasures are recognized in literature. The first one includes in-car technologies, such as systems that can detect driver sleepiness through monitoring drivers' eye and head movements. However, such systems have a significant limitation, which is the weakness to account for individual driver characteristics (Liu et al., 2009). The second category refers to road-related countermeasures, and the most widely used techniques regard edge or centreline rumble devices (Anund et al., 2008), and surfacing of the road shoulders with different coloured asphalt (Rosey et al., 2008).

Driver related countermeasures, which is the third category of interventions to combat fatigue, seem to be the most logical and probably most effective methods to reduce fatigue related accidents (Merat \& Jamson, 2013), since these methods foresee that drivers are sufficiently educated, trained and informed about the risks arising when driving under fatigue, as well as about the scientifically sound means to prevent or encounter fatigue. The ultimate objective of these programs is the elimination or reduction of crashes and the ensurance of drivers' safety and products' security. Even if the concept of safety programmes seems to be inspiring, their practical implementation, mainly affected by economic reasons, is still limited.

Acknowledging the findings of the above state-of-the-art review, which revealed that driving fatigue is a leading factor of road accidents, as well as that professional drivers are at a high risk of road 
accidents, including those fatigue-related, the aim of this paper is to assess the impact of a training program on driving fatigue, targeting 162 professional drivers of a leading company in building materials in Greece.

\section{Method}

\subsection{Design and realization of the training program}

Within the framework of accomplishing educational and research activities and undertaking initiatives for the promotion of traffic safety, the Transportation Engineering Laboratory of the University of Thessaly, organized training program on driving fatigue, aiming at raising awareness of professional drivers on a leading company in building materials in Greece. The one-month educational program took place in eight cities, where the company is established, ensuring national geographical coverage and trained 162 employees in total.

Taking into consideration that, even though drivers have the ability to recognize when they feel tired or sleepy, still a significant number of them keep driving under fatigue (Horne \& Baulk, 2004), the objectives of the training program were to raise knowledge of the effective countermeasures for fatigue (i.e. to stop and rest) and persuasion for avoiding ineffective solutions, to increase risk perception when driving tired, to increase intention for taking a short break when feeling tired, and to increase the number of drivers who take a short break when they feel tired, and decrease the proportion of those drivers who use other solutions.

The training program involved a 2-hour lecture by the trainer, which included the following sections: the physiological basis of fatigue (i.e. sleep loss and recovery, influence of the circadian biological clock, the effects of shift work, etc.); the regulatory framework and legislation regarding professional driving (duration of continuous driving, expected breaks, etc.); the impact of fatigue on driving skills and crash risk; recommendations for personal countermeasure strategies and company policies, and introduction to suspected sleep disorders and referral to specialist treatment. An open discussion session followed after the lecture, during which drivers expressed their personal experiences about driving under fatigue and the solutions they usually choose to adopt in order to encounter sleepiness or tiredness. Each driver received a folder with the training materials for later reference.

\subsection{Evaluation design}

For the achievement of high reliability and the measurability of the effectiveness, the design of the evaluation of an intervention, i.e. training program, should be based on a scientific design, such as experimental (random sampling) or quasi experimental designs (Fylan et al., 2006). At least two periods of measurements, one before and the second after the implementation of the program allow the indication of any changes in driving behavior or accidents rates attributed to the realization of the training program. Such measurements are related to attitudes, subjective and descriptive norms, perceived behavioral control and intentions along with behavior (Fylan et al., 2006).

In addition, there is strong evidence in literature that the adoption of a theoretical background works effectively when designing and evaluating a road safety program, such as campaigns or training activities (Forward et al., 2009). Theory of Planned Behavior (TPB) (Ajzen, 1991) was selected as the theoretical model for the construction of the measurement variables and the development of the questionnaire, which was the technique used for the data collection. TPB associates human behavior with attitude and intention, taking into account the effect of social norms in the prediction of the behavior (Ajzen, 1991).

The measurements of the above constructs were obtained from a structured questionnaire survey, which was conducted before and after the training program. Specifically, right before the beginning of the training lecture that was given in each of the eight venues of the company, a face-to-face questionnaire survey was conducted to the trainees. The total sample that participated in the training program and survey consisted of 162 male drivers with an age of $44.08 \pm 10.5$ years (mean \pm standard deviation). The majority of participants $(74,4 \%)$ drives every day, $17.5 \%$ of them $3-5$ times a week, $6.9 \% 2-5$ times a week, and the rest of them less frequently thus $0.55 \%$ once a week and $0.55 \%$ less often. Achieving a response rate of $87.7 \%, 142$ out of the 162 above drivers replied and mailed back to the Laboratory a second questionnaire, which had been distributed to them two months after the program. Although the 
questionnaires were anonymous, the use of a coding system ensured the pairwise data collection before and after the program implementation.

The structure of the questionnaire, apart from demographics, included the appropriate questions in order to measure specific variables explaining behavior, such as knowledge, behavioral and control beliefs, behavioral intentions, descriptive norms, risk comprehension, past behavior and self-reported behavior. The core part of the questionnaire was responded using a 7-point scale, ranging from 1 (Strongly disagree/very unlikely/not at all/never) to 7 (Strongly agree/very likely/a lot/always), depending on the topic addressed.

Analytically, the variables tested, the statements or questions expressing them and their coding is presented in Table 1:

Table 1: Variable classification

\begin{tabular}{|c|c|c|c|}
\hline Statements or questions expressing: & Code & Statements or questions expressing: & Code \\
\hline Knowledge about: & $K N$ & Control beliefs & $C$ \\
\hline Main factors causing driving fatigue & KN1 & $\begin{array}{l}\text { I would stop and rest or plan my trip, if } \\
\text { there were more police controls }\end{array}$ & $\mathrm{C} 1$ \\
\hline Main signs of fatigue & KN2 & $\begin{array}{l}\text { I would stop and rest or plan my trip, if I } \\
\text { had faced a bad experience in my family or } \\
\text { work environment }\end{array}$ & $\mathrm{C} 2$ \\
\hline The most effective solution to fatigue & KN3 & $\begin{array}{l}\text { I would stop and rest or plan my trip, if } \\
\text { there were more information / raising } \\
\text { awareness campaigns or training programs }\end{array}$ & $\mathrm{C} 3$ \\
\hline $\begin{array}{l}\text { The high likelihood of get involved in a crash } \\
\text { when driving tired }\end{array}$ & KN4 & Descriptive norms & $D N$ \\
\hline Behavioural beliefs & $B B$ & $\begin{array}{l}\text { My colleagues stop and rest during their } \\
\text { trip }\end{array}$ & \\
\hline A good solution to fatigue is to drink a coffee & BB1 & Past behavior & $P B$ \\
\hline $\begin{array}{l}\text { A good solution to fatigue is to open the window } \\
\text { for fresh air }\end{array}$ & BB2 & Frequency of driving tried in the last month & PB1 \\
\hline A good solution to fatigue is to listen to music & BB3 & $\begin{array}{l}\text { Frequency of falling asleep or almost } \\
\text { falling asleep at the wheel in the last month }\end{array}$ & PB2 \\
\hline A good solution to fatigue is to stop and rest & BB4 & $\begin{array}{l}\text { Frequency of falling asleep at the wheel and } \\
\text { got involved in a crash }\end{array}$ & PB3 \\
\hline A good solution to fatigue is to plan your trip & BB5 & $\begin{array}{l}\text { Frequency of sleeping less than six hours } \\
\text { the night before your trip }\end{array}$ & PB4 \\
\hline Risk comprehension about: & $R S$ & Self-reported behavior & $B$ \\
\hline $\begin{array}{l}\text { Getting involved in an accident or causing an } \\
\text { accident }\end{array}$ & RS & When I get tired, I stop and rest & B1 \\
\hline Behavioural intentions & INT & When I get tired, I drink a coffee & B2 \\
\hline $\begin{array}{l}\text { When tired in the next month, I intend to stop and } \\
\text { rest }\end{array}$ & INT1 & When I get tired, I listen to music & B3 \\
\hline I intend to plan my next trips & INT2 & When I get tired, I open the window & B4 \\
\hline $\begin{array}{l}\text { When tired in the next month, I intend to follow } \\
\text { other countermeasures }\end{array}$ & INT3 & & \\
\hline $\begin{array}{l}\text { When tired in the next month, I intend to drive } \\
\text { anyway }\end{array}$ & INT4 & & \\
\hline $\begin{array}{l}\text { When tired in the next month, I intend to quit my } \\
\text { trip }\end{array}$ & INT5 & & \\
\hline
\end{tabular}

\subsection{Data analysis}

For the data analysis, both descriptive and inferential statistics were used. In the first case, a number of the sample characteristics, such as age, the years owning a professional driving licence, the frequency of driving, etc. were analyzed, by estimating mean values and standard deviations. Regarding inferential statistics, the statistical analysis of the responses was carried out using nonparametric tests, which are regarded as particularly powerful for analyzing data collected through questionnaire surveys (Siegel \& Castellan, 1988). 
Hypothesis testing was used to assess any differences in driving behavior before and after the training program realization. The null hypothesis $\mathrm{H}_{0}$ was that the median difference between the pairs is zero, and the alternative hypothesis $\mathrm{H}_{1}$ was that the median difference is not zero. Chi-square $\left(\mathrm{X}^{2}\right)$ test for homogeneity was used to test differences in characteristics measured by categorical variables (i.e. "yes", "no"), while Wilcoxon Signed-Rank Test was performed to assess differences between the samples in characteristics measured on the 7-point scale. A confidence level of $95 \%$ and confidence interval of 5\% were assumed.

Lastly, in order to investigate the inter-relationships between the individual measurement variables and their relationship with the self-reported variables, bivariate correlations were conducted. In addition, for the development of prediction modes, linear regression analyses were used.

\section{Results}

\subsection{Impact assessment of the training program on driving behavior}

In this section, the results of the assessment of the impact of the training program on driving behavior are presented, addressed by the relevant measurement variables tested. Specifically, knowledge is described by 4 categorical variables, each of which had two mutually exclusive alternatives thus, "Yes" or "No", while, the trainees also indicated their perceptions, on a 7-point scale, in 23 ordinal variables, 5 addressing behavioral beliefs, 1 risk comprehension, 5 behavioral intentions, 3 control beliefs, 1 descriptive norms, 4 past behavior and 4 self-reported behavior.

As far as knowledge is concerned, results showed a significant increase of the proportion of the trainees who were aware of the effects of fatigue on driving after the training program (99.3\%), compared to the proportion before the program realization $(98.6 \%)(\mathrm{p}$-value $=0)$. Similar results were indicated when testing the proportion of the trainees who were aware about the most effective solution to fatigue thus, to stop and rest, and the relevant rates were $92.3 \%$ and $99.3 \%$ in the before and after phases (pvalue $=0.001$ ), respectively. As far as the knowledge on the factors that cause fatigue and that driving tired could involve them to a crash, it was observed that all trainees had already this knowledge before the training program implementation.

The positive impact of the training program was, also, observed, when testing the ordinal variables. In this case, Wilcoxon Signed-Rank tests were performed and the results are summarized in Table 1, in which the average ratings for each variable before and after the training program are presented, as well as the $\mathrm{z}$-statistic, the calculated effect size $(\mathrm{r}=\mathrm{Z} / \sqrt{\mathrm{N}}$, where $\mathrm{N}$ is the total number of observations) and p-value, indicating the strength of the respective evidence. Results showed that the average ratings of behavioral beliefs, risk comprehension and behavioral intentions, follow the "positive" direction of change, thus, the adoption of effective countermeasures for fatigue, such as trip planning and powernap (Van Dongen et al., 2003), while, other countermeasures that are falsely used, such as coffee drinking, listening to music, etc. (Heatherley, 2011) seem to be preferred less by drivers, after the training program.

Also, an increase was indicated in the values of variables addressing control beliefs after the training program, showing that if enforcement was stricter $(r=-0.1$, $p$-value $=0.077)$ or if someone of the family or work environment of the trainees had a bad experience on the roads due to fatigue ( $\mathrm{r}=-0.03$, $\mathrm{p}$ value $=0.614$ ), that would raise their awareness and urge them to safer driving. In addition, results showed an increase after the program implementation in trainees' responses referring to their colleagues who stop and rest when tired $(\mathrm{r}=-0.04$, $\mathrm{p}$-value $=0.523)$.

On the other hand, a decrease was observed in the frequency of the trainees that drive under fatigue $(\mathrm{r}=-0.05, \mathrm{p}$-value $=0.381)$, the frequency of falling or almost falling asleep at the wheel $(\mathrm{r}=-0.04, \mathrm{p}$ value $=0.515)$ and the frequency of falling asleep and getting involved in a crash $(r=-0.05, p$-value $=0.441)$. Although these differences before and after the program implementation were not statistically significant, however, the average ratings show that the frequency of risky behavior was already low before the program.

Finally, as regards self-reported behavior, results showed that the training program affected positively the direction of change in the behavior of the trainees, since a significant increase was indicated in the adoption of the proposed by the program effective countermeasure thus to stop and rest when tired $(\mathrm{r}=-0.17$, $\mathrm{p}$-value $=0.004)$, while a relevant significant reduction was observed in other countermeasures that are falsely used, i.e. coffee drinking $(r=-0.24$, $\mathrm{p}$-value $=0)$, listening to music $(\mathrm{r}=-0.22$, $\mathrm{p}$-value $=0)$ and opening the window $(\mathrm{r}=-0.26$, $\mathrm{p}$-value $=0)$. 
Table 2: Average rating and summary of test results for comparison between the phases of the training program

\begin{tabular}{|c|c|c|c|c|c|}
\hline \multirow{2}{*}{ Ordinal variables } & \multicolumn{2}{|c|}{ Average rating } & \multirow{2}{*}{ z-statistic } & \multirow{2}{*}{ Effect size (r) } & \multirow{2}{*}{$\begin{array}{l}\text { p-value } \\
\text { B vs. A }\end{array}$} \\
\hline & B & $\mathbf{A}$ & & & \\
\hline \multicolumn{6}{|c|}{ Behavioral beliefs: “A good solution to fatigue is to...” } \\
\hline Drink a coffee & 3.57 & 2.94 & -3.338 & -0.2 & $0.001 *$ \\
\hline Open the window for fresh air & 4.14 & 3.40 & -3.763 & -0.22 & $0^{*}$ \\
\hline Listen to music & 3.26 & 2.48 & -4.344 & -0.26 & $0^{*}$ \\
\hline Stop and rest for $15-20$ minutes & 5.92 & 6.13 & -1.033 & -0.06 & 0.301 \\
\hline Plan my trip & 6.15 & 6.53 & -2.476 & -0.15 & $0.013^{*}$ \\
\hline \multicolumn{6}{|l|}{ Risk comprehension about: } \\
\hline Getting involved or causing an accident & 6.15 & 6.51 & -1.893 & -0.11 & 0.058 \\
\hline \multicolumn{6}{|c|}{ Behavioral intentions: “When tired in the next month, I intend to..." } \\
\hline Stop and rest for $15-20$ minutes & 5.15 & 6.44 & -6.054 & -0.4 & $0^{*}$ \\
\hline Plan my trip & 5.98 & 6.51 & -3.016 & -0.18 & $0.003^{*}$ \\
\hline Follow other solutions & 4.25 & 3.61 & -2.643 & -0.16 & $0.008^{*}$ \\
\hline Drive anyway & 3.85 & 2.86 & -4.070 & -0.24 & $0 *$ \\
\hline Interrupt my trip & 4.55 & 6.09 & -6.135 & -0.36 & $0^{*}$ \\
\hline \multicolumn{6}{|c|}{ Control beliefs: "I would stop and rest or I would plan my trip, if..." } \\
\hline Enforcement was more strict & 4.33 & 4.75 & -1.766 & -0.1 & 0.077 \\
\hline $\begin{array}{l}\text { Someone of my family or colleagues } \\
\text { had a bad experience }\end{array}$ & 4.83 & 4.91 & -0.504 & -0.03 & 0.614 \\
\hline $\begin{array}{l}\text { Campaigns or training programs were } \\
\text { implemented more often }\end{array}$ & 5.39 & 5.36 & -0.221 & -0.01 & 0.825 \\
\hline \multicolumn{6}{|l|}{ Descriptive norms: } \\
\hline $\begin{array}{l}\text { My colleagues stop and rest during their } \\
\text { trip }\end{array}$ & 5.05 & 5.13 & -0.639 & -0.04 & 0.523 \\
\hline \multicolumn{6}{|l|}{ Past behavior: } \\
\hline Frequency of driving under fatigue & 2.20 & 2.09 & -0.876 & -0.05 & 0.381 \\
\hline $\begin{array}{l}\text { Frequency of falling asleep or almost } \\
\text { falling asleep at the wheel }\end{array}$ & 1.29 & 1.23 & -0.652 & -0.04 & 0.515 \\
\hline $\begin{array}{l}\text { Frequency of falling asleep and getting } \\
\text { involved in a crash }\end{array}$ & 1.11 & 1.06 & -0.770 & -0.05 & 0.441 \\
\hline $\begin{array}{l}\text { Frequency of sleeping less than } 6 \text { hours } \\
\text { before a planned trip }\end{array}$ & 2.94 & 2.77 & -0.768 & -0.05 & 0.443 \\
\hline \multicolumn{6}{|c|}{ Self-reported behavior: "When I get tired..." } \\
\hline I stop and rest for 15-20 minutes & 6.15 & 6.50 & -2.880 & -0.17 & $0.004 *$ \\
\hline I drink a coffee & 4.28 & 3.44 & -4.052 & -0.24 & $0^{*}$ \\
\hline I listen to music & 3.73 & 2.99 & -3.725 & -0.22 & $0^{*}$ \\
\hline I open the window & 5.01 & 4.08 & -4.452 & -0.26 & $0^{*}$ \\
\hline
\end{tabular}

\subsection{Inter-relationships between measurement variables}

Based on the main objectives of the training program thus to increase the awareness of the professional drivers (trainees) that the most effective solution to encounter fatigue is to stop and rest when feeling tired, and, on the other hand, to decrease the number of drivers who follow other ineffective countermeasures when tired, i.e. to drink a coffee, listen to music or open the window for fresh air, two alternative tests were run, respectively. For the needs of the present paper, these tests were based on the responses of the drivers after the implementation of the training program. Taking into account the number of trainees who completed all fields of the questionnaire, the sample size was 136 drivers. 
Applying the first test, an effort was made to investigate the inter-relationships between a number of measurement variables and their relationship with the variable addressing self-reported behavior towards stopping and resting when tired. In addition, the first test included the development of a model predicting the impact of the training program in terms of affecting drivers to stop and rest whey they get tired.

On the other hand, the aim of the second test was to investigate the inter-relationships between a number of measurement variables and their relationship with the variable addressing self-reported behavior towards following other solutions to fatigue than stopping and resting. Once again, a prediction model was developed associated with the effectiveness of the program to convince drivers not to use ineffective solutions when they have to deal with fatigue.

Table 3 presents the bivariate correlations of the individual variables and their relationship with the variable addressing self-reported behavior towards stopping and resting. In this case, the dependent variable thus self-reported behavior towards stopping and resting (variable B1 of Table 1) was correlated with behavioral belief that a good solution to fatigue is to stop and rest (variable BB4 of Table 1), risk comprehension about getting involved in an accident or causing an accident (variable RS of Table 1), control belief addressing drivers beliefs on whether they would stop and rest or plan their trips in case there were more police controls (variable $\mathrm{C} 1$ of Table 1), if they had faced a bad experience in their family or work environment (variable C2 of Table 1) or if there were more information / raising awareness campaigns or training programs (variable C3 of Table 1) and descriptive norm addressing drivers' perception on actual situations, such as "My colleagues stop and rest during their trip" (variable $\mathrm{DN}$ of Table 1). Also, B1 was correlated with variables addressing past behavior of drivers, and in this case, using alpha test (Cronbach, 1951) the responses of drivers about the frequency of driving tired in the last month (variable PB1 of Table 1), the frequency of falling asleep or almost asleep at the wheel in the last month (variable PB2 of Table 1) and the frequency of falling asleep at the wheel and got involved in a crash (variable PB3 of Table 1) were combined into one variable, hereinafter PB123, with a value of Cronbach alpha equal to 0.6 . The fourth variable (variable PB4 of Table 1) regarding the frequency of sleeping less than six hours the night before the trip was used individually. The last variable was the age of drivers, and three clusters were defined: 18-25 years old, 26-50 years old, and over 50 years old.

Table 3: Bivariate correlations of the individual variables and their relationship with the variable addressing self-reported behavior towards stopping and resting when tired

\begin{tabular}{|c|c|c|c|c|c|c|c|c|c|c|c|c|}
\hline Variables & Code & 1. & 2. & 3. & 4. & 5. & 6. & 7. & 8. & 9. & 10. & 11. \\
\hline $\begin{array}{l}\text { 1. Self-reported } \\
\text { behavior_1 }\end{array}$ & B1 & - & & & & & & & & & & \\
\hline $\begin{array}{l}\text { 2. Behavioral } \\
\text { belief_4 }\end{array}$ & BB4 & .3 & - & & & & & & & & & \\
\hline $\begin{array}{l}\text { 3. Risk } \\
\text { comprehension }\end{array}$ & RS & .15 & .04 & - & & & & & & & & \\
\hline $\begin{array}{l}\text { 4. Behavioral } \\
\text { intention_1 }\end{array}$ & INT1 & $.25^{* *}$ & .17 & $.31 * *$ & - & & & & & & & \\
\hline 5. Control belief_1 & $\mathrm{C} 1$ & -.04 & $.28 * *$ & .06 & .08 & - & & & & & & \\
\hline 6. Control belief_2 & $\mathrm{C} 2$ & -.04 & .03 & .03 & .14 & $.29 * *$ & - & & & & & \\
\hline 7. Control belief_3 & $\mathrm{C} 3$ & -.02 & $.19^{*}$ & .16 & .12 & $.42 * *$ & $.26^{* *}$ & - & & & & \\
\hline $\begin{array}{l}\text { 8. Past } \\
\text { behavior_123 }\end{array}$ & PB123 & $-.28 * *$ & .14 & -.16 & $\begin{array}{l}.27 * * \\
.\end{array}$ & -.05 & -.09 & -.13 & - & & & \\
\hline 9. Past behavior_4 & PB4 & $-.23 * *$ & $-.17 *$ & $-.2 *$ & $-.21 *$ & -.11 & -.02 & -.12 & $.3 * *$ & - & & \\
\hline $\begin{array}{l}\text { 10. Descriptive } \\
\text { norm }\end{array}$ & $\mathrm{DN}$ & $.3 * *$ & .05 & .12 & .17 & .07 & .09 & .12 & -.13 & -.08 & - & \\
\hline 11. Age & AGE & .15 & -.04 & .02 & .1 & .15 & $.22 *$ & $.25^{* *}$ & $-.2 *$ & -.1 & $.19 *$ & - \\
\hline \multicolumn{13}{|l|}{${ }^{*} p$-value $<.05$} \\
\hline \multicolumn{13}{|l|}{$*^{* *} p$-value $<.01$} \\
\hline
\end{tabular}

Results showed that behavioral intention and descriptive norm are significantly correlated with the variable addressing self-reporting behavior towards stopping and resting when tired (Table 3). Positive relationships were also observed between behavior and behavioral belief, risk comprehension and age, 
however these correlations were not significant. On the other hand, a negative relationship was indicated between behavior and the variables referring to past behavior and intention, showing that when the values of behavior increase, the values of past behavior and control beliefs decrease.

Focusing on the second test that was conducted, the dependent variable was self-reported behavior towards following other solutions to fatigue than stopping and resting, and was constructed by the combination of the variables B2, B3 and B4 of Table 1 (hereinafter B234), which record self-reported behavior of the drivers who choose to drink a coffee, listen to music and open the window for fresh air, when they get tired while driving. For the combination of B2, B3 and B4, alpha test was used again and the Cronbach alpha value was equal to 0.89 . Similarly, behavioral beliefs in this case was constructed by the combination of variables BB1, BB2 and BB3 of Table 1 (hereinafter BB123), and Cronbach a was calculated to 0.87 . The dependent variable was also correlated with the variable expressing drivers' intention to follow other countermeasures to deal with fatigue (variable INT3 of Table 1), while risk comprehension (RS), control beliefs (C1, C2 and C3), past behavior (PB123 and PB4) and age were the same variables as those used in the first test. The results of the bivariate correlations of the above measurement variables and their relationship with the dependent variable adressing self-reported behavior towards following other solutions to fatigue, i.e. drinking a coffee, listening to music and opening the window for fresh air, are presented in Table 4.

Table 4: Bivariate correlations of the individual variables and their relationship with the variable addressing self-reported behavior towards following other solutions to fatigue than stopping and resting when tired

\begin{tabular}{|c|c|c|c|c|c|c|c|c|c|c|c|c|}
\hline Variables & Code & 1. & 2. & 3. & 4. & 5. & 6. & 7. & 8. & 9. & 10. & 11. \\
\hline $\begin{array}{l}\text { 1. Self-reported } \\
\text { behavior_234 }\end{array}$ & B234 & - & & & & & & & & & & \\
\hline $\begin{array}{l}\text { 2. Behavioral } \\
\text { belief_123 }\end{array}$ & $\mathrm{BB} 123$ & $.75^{* *}$ & - & & & & & & & & & \\
\hline $\begin{array}{l}\text { 3. Risk } \\
\text { comprehension }\end{array}$ & RS & $-.17 *$ & -.12 & - & & & & & & & & \\
\hline $\begin{array}{l}\text { 4. Behavioral } \\
\text { intention_3 }\end{array}$ & INT3 & $.72 * *$ & $.69 * *$ & $.26 * *$ & - & & & & & & & \\
\hline 5. Control belief_1 & $\mathrm{C} 1$ & .09 & .05 & .06 & .1 & - & & & & & & \\
\hline 6. Control belief_2 & $\mathrm{C} 2$ & $-.2 *$ & -.12 & .03 & $.25 * *$ & $.29 * *$ & - & & & & & \\
\hline 7. Control belief_3 & $\mathrm{C} 3$ & -.09 & -.02 & .16 & -.08 & $.42 * *$ & $.26 * *$ & - & & & & \\
\hline $\begin{array}{l}\text { 8. Past } \\
\text { behavior_123 }\end{array}$ & PB123 & $.36 * *$ & .16 & -.16 & $.17^{*}$ & -.05 & -.09 & -.13 & - & & & \\
\hline 9. Past behavior_4 & PB4 & $.26 * *$ & $.19 *$ & $-.2 *$ & $.26 * *$ & -.11 & -.02 & -.12 & $.33 * *$ & - & & \\
\hline $\begin{array}{l}\text { 10. Descriptive } \\
\text { norm }\end{array}$ & DN & $-.25^{* *}$ & -.14 & .12 & .13 & .07 & .09 & .12 & -.13 & -.08 & - & \\
\hline 11. Age & AGE & -.09 & -.06 & .02 & -.07 & .15 & $.22 *$ & $.25^{* *}$ & $-.2^{*}$ & -.1 & $.19 *$ & - \\
\hline \multicolumn{13}{|l|}{${ }^{*} p$-value $<.05$} \\
\hline$* * p$-value $<.01$ & & & & & & & & & & & & \\
\hline
\end{tabular}

Based on the findings of Table 4, it was observed that behavioral belief (BB123), behavioral intention (INT3) and past behavior (PB123, PB4) were significantly correlated with self-reported behavior (B234). Positive relationship was also indicated between behavior and control belief_1 (C1), but this correlation was not significant. On the other hand, negative relationships were observed between behavior and the variables addressing risk comprehension, control belief 2 and descriptive norm, and these negative correlations were significant. Lastly, negative relationships were indicated between behavior and control belief_3 and age, however these correlations were not significant.

\subsection{Prediction model development and testing}

The last objective of this study was to develop prediction models in order to investigate which factors are associated with the likelihood of drivers to stop and rest when they get tired while driving, as well as the respective likelihood of drivers to follow other solutions to deal with fatigue, such as to drink a coffee, listen to music or open the window for fresh air. The results of the two prediction models are presented in Tables 5 and 6 . 
In the first case, behavioral belief_4 (BB4), risk comprehension (RS), behavioral intention_1 (INT1), control belief_1 (C1), control belief_2 (C2), control belief_3 (C3), past behavior (PB123 and PB4), descriptive norm (DN) and age were used as predictors of the dependent variable thus self-reported behavior towards stopping and resting when tired. Results showed that the strongest, statistically significant, predictor was descriptive norm. The overall model was a significant predictor of behavior $(\mathrm{F}(10,135)=1.955, \mathrm{p}$-value $<.05))$ and accounted for $10 \%$ of the variance. Analytically, the relationship of each predictor with behavior is presented in Table 5 .

Table 5: Linear regression of the individual variables and their relationship with the variable recording self-reported behavior towards stopping and resting when tired

\begin{tabular}{|c|c|c|c|c|c|c|}
\hline Variable & Code & B & Std. Error & Beta & $\mathrm{t}$ & Sig. \\
\hline Behavioral belief_4 & BB4 & -.007 & .048 & -.013 & -.140 & .889 \\
\hline Risk comprehension & RS & .095 & .092 & .090 & 1.032 & .304 \\
\hline Behavioral intention_1 & INT1 & .119 & .076 & .136 & 1.560 & .121 \\
\hline Control belief_1 & $\mathrm{C} 1$ & .0 & .041 & -.001 & -.012 & .991 \\
\hline Control belief_2 & $\mathrm{C} 2$ & -.047 & .035 & -.119 & -1.344 & .182 \\
\hline Control belief_3 & $\mathrm{C} 3$ & -.038 & .053 & -.072 & -.730 & .467 \\
\hline Past behavior_123 & PB123 & -.145 & .113 & -.116 & -1.281 & .203 \\
\hline Past behavior_4 & PB4 & -.018 & .039 & -.041 & -.407 & .639 \\
\hline Descriptive norm & $\mathrm{DN}$ & .102 & .047 & .186 & 2.174 & $.032 *$ \\
\hline Age & AGE & .185 & .157 & .105 & 1.175 & .242 \\
\hline Constant & & 4.886 & .921 & & 5.307 & 0 \\
\hline \multicolumn{7}{|c|}{ Adjusted $R^{2}=1 ; F(10,125)=1.955 *$} \\
\hline \multicolumn{7}{|l|}{$* p$-value $<.05$} \\
\hline
\end{tabular}

On the other hand, focusing on the model tested for predicting behavior towards following other solutions to fatigue than stopping and resting, it was observed that behavioral beliefs, behavioral intention and past behavior were significant predictors of behavior, with behavioral belief being the strongest one. The overall model was a significant predictor of behavior $(\mathrm{F}(10,135)=30.508$, p-value $<.01))$ and accounted for $69 \%$ of the variance. Analytically, the relationship of each predictor with behavior is presented in Table 6.

Table 6: Linear regression of the individual variables and their relationship with the variable recording self-reported behavior towads following other solutions to fatigue than stopping and resting when tired

\begin{tabular}{|c|c|c|c|c|c|c|}
\hline Variable & Code & B & Std. Error & Beta & $\mathbf{t}$ & Sig. \\
\hline Behavioral belief_123 & BB123 & .558 & .075 & .490 & 7.409 & $0 * *$ \\
\hline Risk comprehension & RS & .058 & .114 & .026 & 0.513 & 0.609 \\
\hline Behavioral intention_3 & INT3 & .259 & .058 & .317 & 4.453 & $0 * *$ \\
\hline Control belief_1 & $\mathrm{C} 1$ & .066 & .050 & .075 & 1.328 & .187 \\
\hline Control belief_2 & $\mathrm{C} 2$ & -.036 & .044 & -.043 & -.810 & .420 \\
\hline Control belief_3 & $\mathrm{C} 3$ & -.037 & .062 & -.033 & -.593 & .554 \\
\hline Past behavior_123 & PB123 & .545 & .135 & .209 & 4.038 & $0 * *$ \\
\hline Past behavior_4 & PB4 & .029 & .047 & .031 & .606 & .545 \\
\hline Descriptive norm & $\mathrm{DN}$ & -.139 & .057 & -.122 & -2.437 & $.016 *$ \\
\hline Age & AGE & .081 & .190 & .022 & .429 & .669 \\
\hline Constant & & .259 & 1.004 & & .258 & .797 \\
\hline \multicolumn{7}{|c|}{ Adjusted $R^{2}=.69 ; F(10,125)=30.508 * *$} \\
\hline \multicolumn{7}{|l|}{$* p$-value $<.05$} \\
\hline
\end{tabular}




\section{Summary and Conclusions}

Fatigue, resulting in falling asleep at the wheel, is considered as one of the leading factors causing road accidents and injuries worldwide (Royal, 2003; NHTSA, 1998; Yakabuski, 2014; Horne \& Reyner, 2000; ETSC, 2001).

The aim of this paper was to assess the impact of a training program on driving fatigue, targeting 162 professional drivers of a leading company in building materials in Greece. For this purpose, a questionnaire survey was conducted, before and after the program realization, and, based on a number of measurement variables, an effort was made to evaluate the degree of penetration of the program on driving performance and the respective proportion of change in driving behavior. In addtion, the interrealtionships between the individual measuresment variables and their relationship with the self-reported variables were tested through bivariate correlations, as well through the development of prediction models.

Results showed a significant increase of the proportion of the trainees who were aware of the effects of fatigue on driving after the program implementation (99.3\%), compared to the proportion before the program $(98.6 \%)$ ( $\mathrm{p}$-value=0). Similar results were observed when testing the proportion of the trainees who were aware about the most effective solution to fatigue, thus to stop and rest, and the relative rates were $92.3 \%$ and $99.3 \%$ in the before and after phases, respectively ( $p$-value $=0.001$ ).

The main message of the program, which was to raise drivers' awareness about the most effective solution to fatigue, was successfully reached by the trainees. Specifically, results showed a significant increase in average rating of drivers' intention to stop and rest for 15-20 minutes ( $\mathrm{p}$-value $=0$ ) and a significant decrease to follow other less effective solutions ( $p$-value $=0.008$ ). The findings of variables testing the self-reported behavior of trainees, revealed that the training program affected their behavior in the positive direction of change, resulting in a statistically significant increase of the average frequency that they stop and rest when they feel tired ( $\mathrm{p}$-value $=0.004$ ).

In addition, results showed that behavioral intention and descriptive norm were significantly correlated with the variable addressing self-reporting behavior towards stopping and resting when tired, while the stongest predictor of behavior was descriptive norm. The overall model in this case was a significant predictor of behavior $(\mathrm{F}(10,135)=1.955, \mathrm{p}$-value $<.05))$ and accounted for $10 \%$ of the variance. On the other hand, focusing on self-reported behavior towards following solutions such as drinking a coffee, listening to music or opening the window for fresh air, it was observed that behavioral beliefs, behavioral intention and past behavior were significantly correlated with behavior, while the strongest predictor of behavior was behavioral belief. The overall model was a significant predictor of behavior $(F(10,135)=30.508, p$-value $<.01))$ and accounted for $69 \%$ of the variance.

\section{References}

1. Ajzen, I. (1991). The theory of planned behavior. Organizational Behavior and Human Decision Processes, 50, 179-211.

2. Anund, A., Kecklund, G., Vadeby, A., Hjälmdahl, M., Ekerstedt, T., 2008. The alerting effect of hitting a rumble strip - a simulator study with sleepy drivers. Accident Analysis and Prevention 40, 1970-1976.

3. Arnold, P.K., Hartley, L.R., Corry, A., Hochstadt, D., Penna, F., Feyer, A.M., 1997. Hours of work, and perceptions of fatigue among truck drivers. Accident Analysis and Prevention 29 (4), 471-477.

4. Blower, D., Campbell, K.L., Green, P.E., 1993. Accident rates for heavy truck-tractors in Michigan. Accident Analysis and Prevention 25 (3), 307-321.

5. CARE, 2014. http://ec.europa.eu/transport/road_safety/specialist/statistics/index_en.htm, retrieved April, 2014.

6. Charbotel, B., Chiron, M., Martin, J.L. \& Bergeret, A., 2001. Work related road accidents in France. European Journal of Epidemiology, 17(8), pp. 773-778.

7. Cronbach, L.J. (1951). Coefficient alpha and the internal structure of tests. Psychometrical, 16 (3), 297-334.

8. ETSC, 2001. The role of driver fatigue in commercial road transport crashes. European Transport Safety Council ETSC, Brussels Accessed 15 January 2008: http://www.etsc.be/oldsite/drivfatigue.pdf.

9. Forward, S. \& Kazemi, A. (Editors), Adamos, G., Ausserer, K., Brijs, K., Brijs, T., Daniels, S., Divjak, M., Haupt, J., Krol, B., Malasek, J., Nathanail, T., Phillips, R. O., Risser, R., Tamis, K., 
Ullberg, P., Vaa T., Zabukovec, V., 2009. A theoretical approach to assess road safety campaigns: Evidence from seven European countries. CAST project. Belgian Road Safety Institute (IBSRBIVV), Brussels, Belgium.

10. Fylan, F., Hempel, S., Grunfeld, B., Conner, M. \& Lawton, R., 2006. Effective interventions for speeding motorists, Road Safety Research Report No. 66. Department for Transport: London.

11. Gkrizioti, M., Mastrokostas, A., Haiditch, A.B. \& Panagopoulou E. \& Benos, A., (2010). Shift Work and Traffic Accidents among Nursing Personnel. Nosileftiki 2010, 49(3): 305-314.

12. Heatherley, S., (2011). Caffeine withdrawal, sleepiness, and driving performance: What does the research really tell us? Nutritional Neuroscience, vol. 12, no. 3, 2011.

13. Hell, W., et al. (1997). Road Inattention and Other Causative Factors in Fatal Highway Crashes. Proceedings of the 41th Annual Conference of the Association for the Advancement of Automotive Medicine, Orlando, USA, November 10-11, 1997.

14. Horne, J. A. and Reyner, L. A. (1995) Sleep related vehicle accidents. British Medical Journal, 310 , $565-567$.

15. Horne, J. \& Reyner, L. 2000. Sleep Related Vehicle Accidents, Sleep Research Laboratory, Loughborough University, 2000.

16. Horne, J. A., \& Baulk, S. D. (2004). Awareness of sleepiness when driving. Psychophysiology, 41, 161-165.

17. Liu, C.C., Hosking, S.G., Lennı, M.G., 2009. Predicting driver drowsiness using vehicle measures: recent insights and future challenges. Journal of Safety Research 40, 239-245.

18. MacLean, A.W., Davies, D.R.T., \& Thiele, K. (2003). The hazards and prevention of driving while sleepy, Sleep Medicine Reviews, 7, 431-437.

19. Maycock, G. (1997). Sleepiness and driving the experience of U.K. car drivers. Accident Analysis and Prevention, 29(4), pp 453-462.

20. McKernon, S. 2008. A literature review on driver fatigue among drivers in the general public. NZ Transport Agency research report 342. 62 pp.

21. Merat, N. \& Jamson, H., 2013. The effect of three low-cost engineering treatments on driver fatigue: A driving simulator study. Accident Analysis and Prevention 50 (2013) 8-15.

22. NHTSA Expert panel on driver fatigue and sleepiness, 1998. Drowsy driving and automobile crashes http://www.nhtsa.dot.gov/people/injury/drowsy driving1/drowsy.html.

23. Oron-Gilad, T., \& Shinar, D. (2000) Driver fatigue among military truck drivers. Transportation Research Part F: Traffic Psychology and Behaviour, 3 (4), 195-209.

24. Otmani, S., Pebayle, T., Roge, J., and Muzet, A. (2005) Effect of driving duration and partial sleep deprivation on subsequent alertness and performance of car drivers. Physiology and Behavior, 84(5), 715-724.

25. Rosey, F., Auberlet, J.-M., Bertrand, J., Plainchault, P., 2008. Impact of perceptual treatments on lateral control during driving on crest vertical curves: a driving simulator study. Accident Analysis and Prevention 40, 1513-1523.

26. Rossi, R., Gastaldi, M.\& Gecchele, G., 2011. Analysis of Driver Task-Related Fatigue Using Driving Simulator Experiments. Procedia - Social and Behavioral Sciences, Vol. 20, 2011, pp. 666675.

27. Royal, Dawn. National Survey of Distracted and Drowsy Driving Attitudes and Behaviors:200 2, Vol 1: Findings. Publication DOT HS 809 566. National Highway Traffic Safety Administration, 2003.

28. Sagberg, F (1999) Road accidents caused by drivers falling asleep, Accident Analysis and Prevention 31 (6), pp. 639-649.

29. Siegel, S., and Castellan, J. (1988). Non parametric statistics for the behavioral sciences, $2^{\text {nd }} \mathrm{ed}$. McGraw - Hill, New York.

30. Toscano, G., Windau, J., 1994. The changing character of fatal work injuries. Monthly Labour Rev., $17-28$.

31. Traffic Administration Bureau of Chinese Public Security Ministry. Statistics Annals of Road Traffic Accident of People's Republic of China (2010). Traffic Administration Bureau of Chinese Public Security Ministry, 2011.

32. Van Dongen, H. P., Maislin, G., Mullington, J. M. and Dinges, D. F. (2003). The cumulative cost of additional wakefulness: dose-response effects on neurobehavioral functions and sleep physiology from chronic sleep restriction and total sleep deprivation. Sleep, 26(2), 117-126. 
33. VicRoads Road Accident Factsheet, viewed April 2014. www.vicroads.vic.gov.au/road safe/index.htm.

34. Yakabuski, M. Insurance Bureau of Canada (IBC). Driver Fatigue: Are You Driving Impaired? http://www.ibc.ca/en/Car_Insurance/Driver_Fatigue/. Accessed April, 2014.

35. Yee, B., Campbell, A., Beasley, R., \& Neill, A. (2002) Sleep disorders: a potential role in New Zealand motor vehicle accidents. Intern Med Journal, 32, pp. 297-304.

36. Zhang H., Yan, X., Wu, C. \& Qui, T., 2014. Effect of Circadian Rhythms and Driving Duration on Fatigue Level and Driving Performance in Professional Drivers. Transportation Research Board 2014 Annual Meeting, January 12-16, 2014, Washington DC. 